IRA-International Journal of Applied Sciences ISSN 2455-4499; Vol.04, Issue 02 (2016)

Institute of Research Advances

Pg. no. 211-225

http://research-advances.org/index.php/IRAJAS

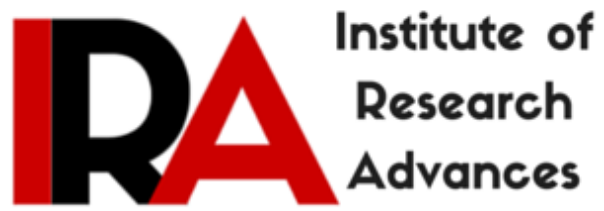

\title{
The Study of Reservoir Zones of Asmari Formation Based on Sequence Stratigraphy and Well-logging Data in a Southwestern Oil Wells of Iran
}

\author{
${ }^{\mathbf{1}}$ Bahman Kiani Shavandi $\boldsymbol{\&}^{\mathbf{2}}$ Vahid Ahmadi \\ ${ }^{1,2}$ Department of Geology, Shiraz Branch, Islamic Azad University, Iran.
}

Type of Review: Peer reviewed.

DOI: http://dx.doi.org/10.21013/jas.v4.n2.p1

\section{How to cite this paper:}

Shavandi, B., \& Ahmadi, V. (2016). The Study of Reservoir Zones of Asmari

Formation Based on Sequence Stratigraphy and Well-logging Data in a Southwestern Oil Wells of Iran. IRA-International Journal of Applied Sciences (ISSN 2455-4499), 4(2), 211-225. doi:http://dx.doi.org/10.21013/jas.v4.n2.p1

(C) Institute of Research Advances

(cc) EY-NG

This work is licensed under a Creative Commons Attribution-Non Commercial 4.0 International License subject to proper citation to the publication source of the work.

Disclaimer: The scholarly papers as reviewed and published by the Institute of Research Advances (IRA) are the views and opinions of their respective authors and are not the views or opinions of the IRA. The IRA disclaims of any harm or loss caused due to the published content to any party. 


\section{ABSTRACT}

Asmari formation in Maroon Oilfield is made up of fossil-bearing limestone, dolomitic limestone, argillaceous limestone, sandstone and shale. It is the main reservoir rock for multiple oil wells of Zagros. The formation in Maroon Oilfield dates back to Oligocene(Rupelian - Burdigalian). In the present study, sequence stratigraphy and depositional environment of Asmari Reservoir Formation located in Maroon Oilfield are studied through well-logging data. The lower limit of Asmari Formation in the studied area is Pabede Formation and its upper limit is Gachsaran Formation. The lower limit between Asmari and Pabede formations and upper limit between Asmari and Gachsaran formations are not continuous and signs of discontinuity are observed in them. The field, macroscopic and microscopic studied and determination of percentage and type of allochem and orthochem elements led to identification of 17 carbonate and clastic facies in Asmari Formation. In the section, 6 depositional sequences were identified and labeled as sequence 1-6. The sequence limits are all of SB2 type with exception of Sequence 6 which is SB1.

Keywords: Asmari Formation, Sequence Stratigraphy, Reservoir Zones.

\section{Introduction}

Today, more than 50 percent of global oil and gas reservoirs is located in carbonate rocks. The rocks host a majority of oil and gas fields in south and southwest of Iran (Zagros Area). In this fields, oligomiocene-aged carbonate rocks (Asmari Formation) constitute significant reservoirs in these regions. Despite of the fact that these calcareous units are generally made up of dense and massive limestone with relatively low initial porosity but due to bearing compression forces and generation of secondary porosities such as numerous cuts, the most significant oil horizons of the region are made in them. Asmari Formation is the primary reservoir rock of crude oil in Dezful Depression. In regard to sequence lithology, the formation was made of limestone, sandstone, shale and rarely evaporative horizons. Lithological characteristics (i.e. context, structure and combination) are one of the most significant parameters in controlling the quality of horizon. These parameters play a significant role in emergence of diagenetic phenomenon in different diagenetic environments. In this regard, analysis of lithological characteristics is among initial requirements of studying the quality of reservoir. On the other hand, lateral and vertical expansion of potential units for the reservoir and their association with adjacent facies could be examined through precise study of depositional environment and dominant condition over it. Modification of facie in dominant condition of depositional environment and factors affecting the development of different depositional groups in a temporal and local framework and through sequence stratigraphy is possible.

\section{Geographical Location of Studied Region}

Maroon Oilfield is one of the largest oilfields of Zagros Area. It is located in southeast of Ahvaz in adjacency of Aghajari, Ahvaz and Koopal oilfields. The field has northwest-southeast direction in western to central parts while it has northeastern-southwestern direction in eastern corner. The length and width of the field were 65 and $7 \mathrm{~km}$ respectively. The surficial facie of this field was Aghajari Formation. The Asmari Formation and Bangestan and Khami groups constitute the oil reservoirs of this field. Asmari Formation is the most significant reservoir rock of this field which is divided into six reservoir layers. Up to now, 320 wells have been drilled in this field. With exception of 6 wells in Khami Reservoir and 17 wells in Bangestan Reservoir, the rest were in Asmari Reservoir (Alizade et al, 2006). 
(a)

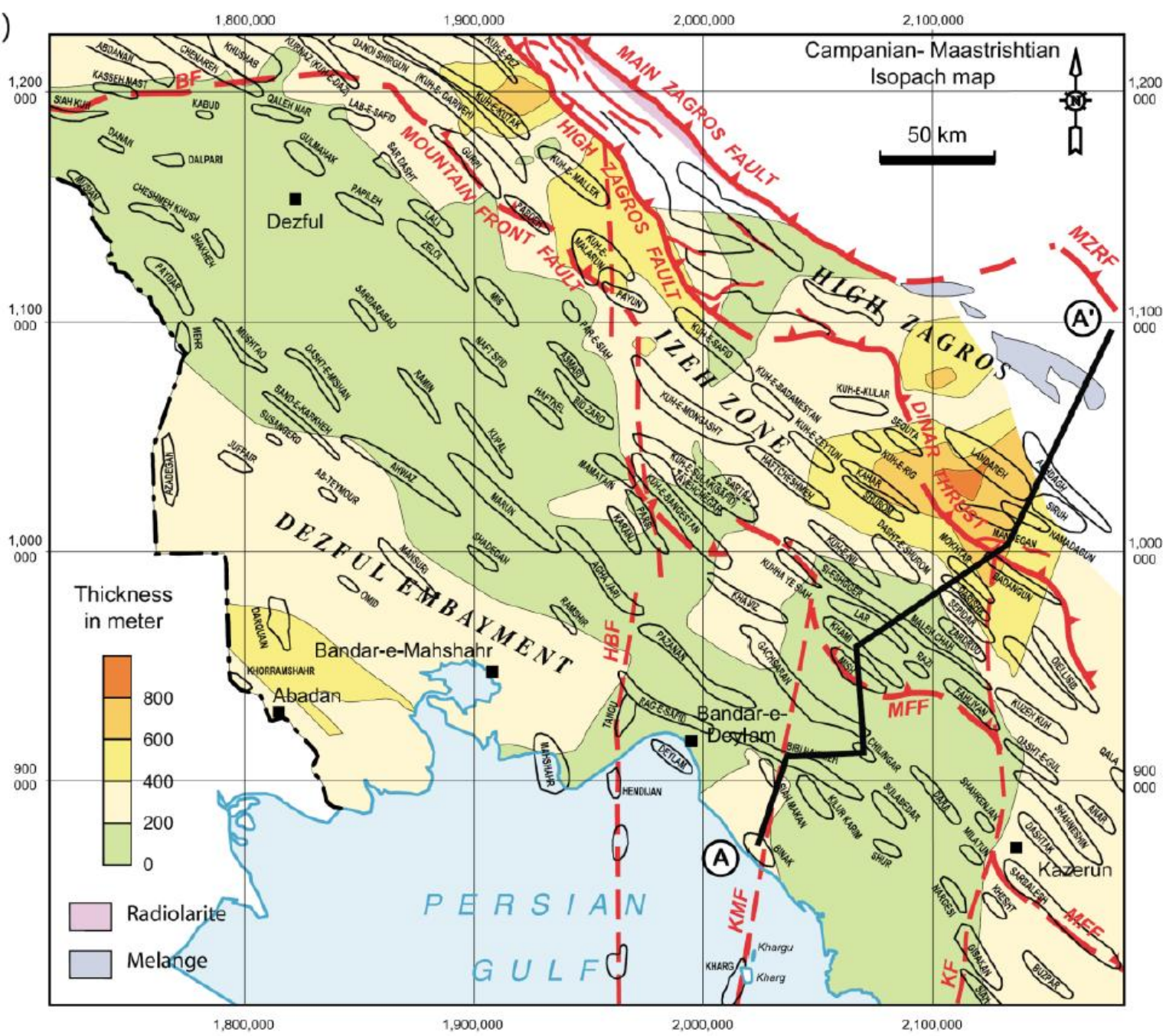

Figure. 1-Geographical location of Maroon Field (Sherkati and Letouzey, 2004)

\section{Methodology}

- Depiction of biostratigraphic distribution of microfossils in relation to stratigraphic column and developing biostratigraphic image.

- Identification and division of biozones and determining precise age through introduced microfossils.

- Identification and introduction of depositional environments through introduced microfacies.

- Studying depositional events, limits and key stratigraphic levels for differentiation of sequences.

- Analysis of obtained results for interpretation and reconstruction of old basic.

- Matching biostratigraphic units of oligomiocene sediments in the studied section with remaining areas of Zagros.

- Matching lithostratigraphic units of oligomiocene sediments in the studied section with remaining areas of Zagros.

- Matching stratigraphic sequence units of oligomiocene sediments in the studied section with remaining areas of Zagros.

- Developing intended profiles and sections with the help of computer software. 


\section{Geology of Zagros Area based on Sedimentary Cycle of Asmari Formation}

Zagros Orogenic Belt is located in the middle part of Alpine orogenic belt. From a perspective of age, it is the youngest Cenozoic orogenies. From viewpoint of plate tectonics, this orogenic belt is regarded as scrambling geodynamic edge of the Arabian plate. Consequently, this fold-thrust belt is considered to be the result of impact of lithospheric Arabian plate against lithospheric block of Iran (southern rim of Eurasia) from late Cretaceous to early Paleocene (Berberian, 1981; Farhudi, 1987; Alavi, 1980; Takin, 1972). Zagros Orogeny is connected to the Iranian block from east. From west, this orogeny is a part of Arabian Plate. At the moment, it is a mountain chain formed in the west and southwest of Iran and it has northwestern-southeastern orientation. The length of this mountain chain inside Iran amounts to 1250 kilometers. Located in northwestern limit of this orogeny, eastern Anatolian slip fault in southwest of Turkey was selected. Oman lineament represents southwest border of Zagros Orogeny (Alvari, 2007; Falcon, 1961).

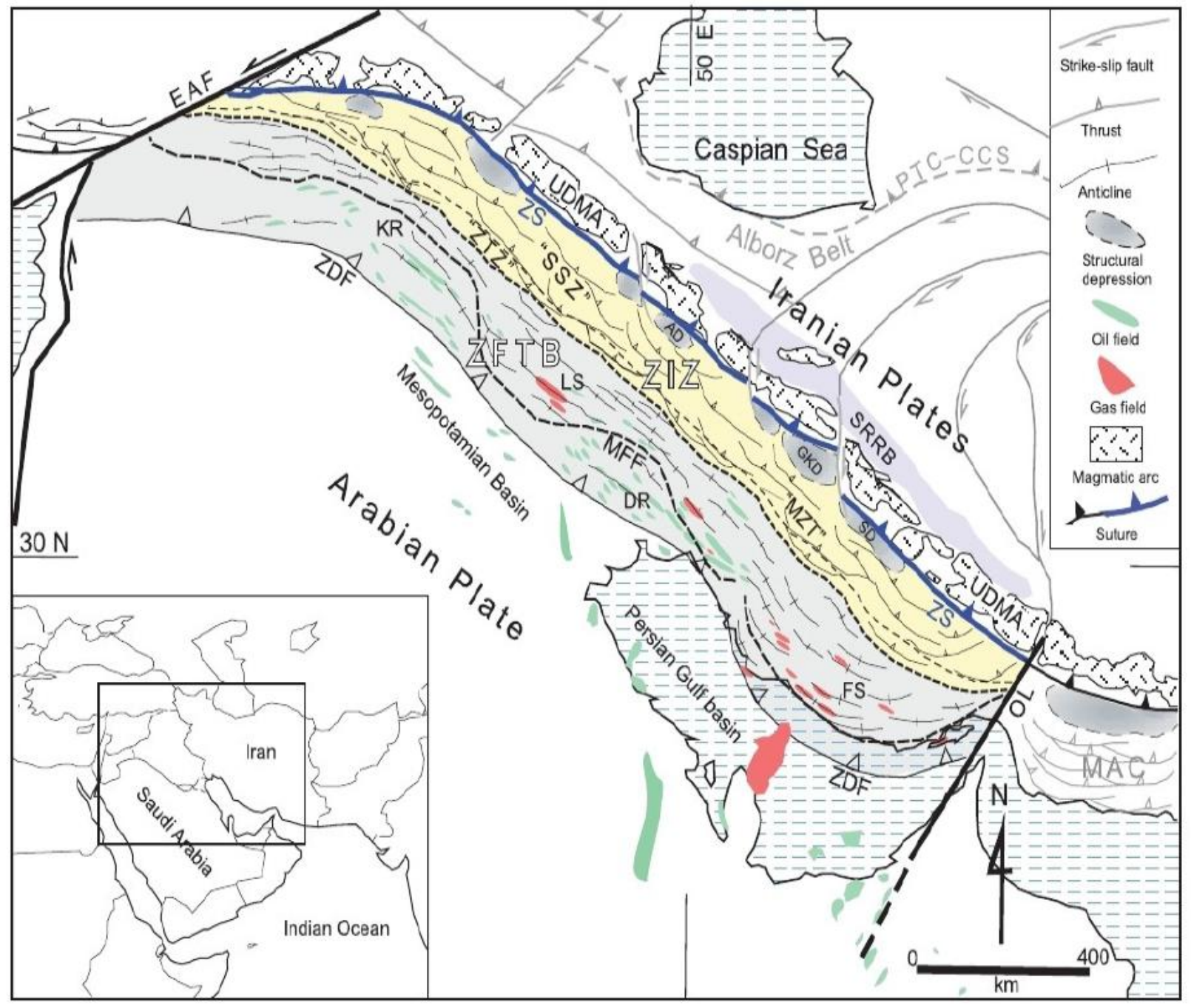

Figure.2-Map of different Zagros subzones from viewpoint of Alvani (2007) (DR: Dezful recess, FS: Fars salient, LS: Lorestan salient, OL: Oman line, MFF: Mountain front flexure, UDMA: UrumiehDokhtar magmatic assemblage, ZDF: Zagros deformational front, ZFTB: Zagros fold-thrust belt, ZIZ: Zagros imbricate zone, ZS: Zagros suture) 
Calcareous Asmari Formation: It is the youngest reservoir rock of Zagros zone and consequently there are extensive studies on lithostratigraphic properties of this formation. In past, this lithological unit was termed Calcareous Jarib Formation, Calcareous Kalhor Formation or Khamir Limestone but these formations refer to a part of modelled section of Asmari Formation. The name of this formation was taken from Asmari Mountain (southeast of Masjid Soleiman) and its sectioning model was measured in TangeGole-Torsh of the same mountain.

In regard to modelled section, Asmari Formation with $314 \mathrm{~m}$ thickness includes resistant limestone with creamy to brown color and orogenic morphology which has some shale interlayers and it is characterized by numerous discontinuities. In the modelled section, Asmari Formation seems to date back to Miocene era. Its lower part is not visible due to change of lateral facie into Pabede Formation. However, the complementary section of this formation in Tang-e-Takab or Khoyar Mountain, 30km away from Behbahab, represents the characteristics of this formation fully.

Asmari limestone is the most significant reservoir rock of depositional zone of Zagros in Iran. Because for the first time in Middle East, oil was discovered in this area it is globally famous. The efficiency of a typical well in an oilfield is relatively good and about 25000 barrels per day (Afshar-Harb, 2002).

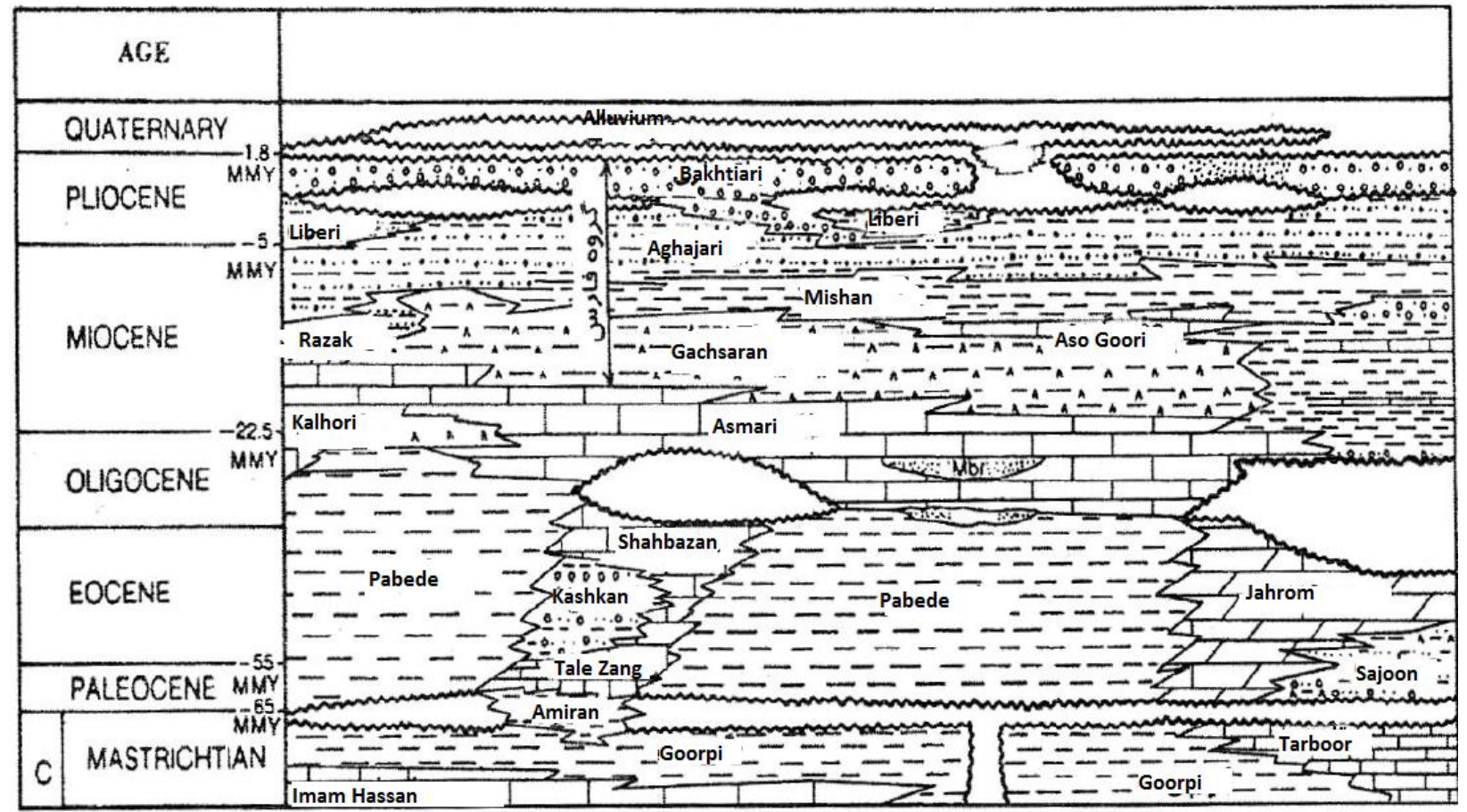

Figure. 3-Spatial and temporal association of Cenozoic stratigraphic units of Zagros (James and Wind, 1965).

\section{Lithostratigraphy of Asmari Formation in Studied Well}

In this well, the Asmari Formation is located on shale-constituted Pabede Formation and below Gachsaran Formation. The lower limit of this formation with Pabede Formation is in the form of a gradual limit on Pabede Formation and with discontinuities below Gachsaran Formation. The thickness of Asmari Formation is $452 \mathrm{~m}$. 
From lithostratigraphic viewpoint, this formation is initially made up of limeous and shale-limeous sequence. The level of Gamma ray $\log (\mathrm{GR})$ in this section is low in limeous parts and higher in shalelimeous part.

Then, shale is placed on this layer which increases the level of logging to 80 API. On this layer, there is silty sand which has low API and then, a shale layer is repeated which adds to the value of logging.

Afterwards, we encounter a layer of sandstone with thickness of $27 \mathrm{~m}$. These layers are called Ahvaz sandstone section. API in this layer reduces when one considers cleanliness of sandstone. Over Ahvaz sandstone part, there are calcareous layers with thickness of $135 \mathrm{~m}$. In this layer, the value of GR is low and ranges between 10 and 20. In lower parts, this variable is low but in upper parts, it increases to 20 API respectively.

Then, a dolomite layer with thickness of $31 \mathrm{~m}$ is observed which is associated with tidal zone and its API is low. This layer is followed by a layer of sandstone with low thickness belonging to coastal zone and its API is about 20. On this layer of sandstone, there is a thin dolomitic limeous layer. This sequence is associated with internal ramp and the value of Gamma ray logging ranges from 10 to 20.

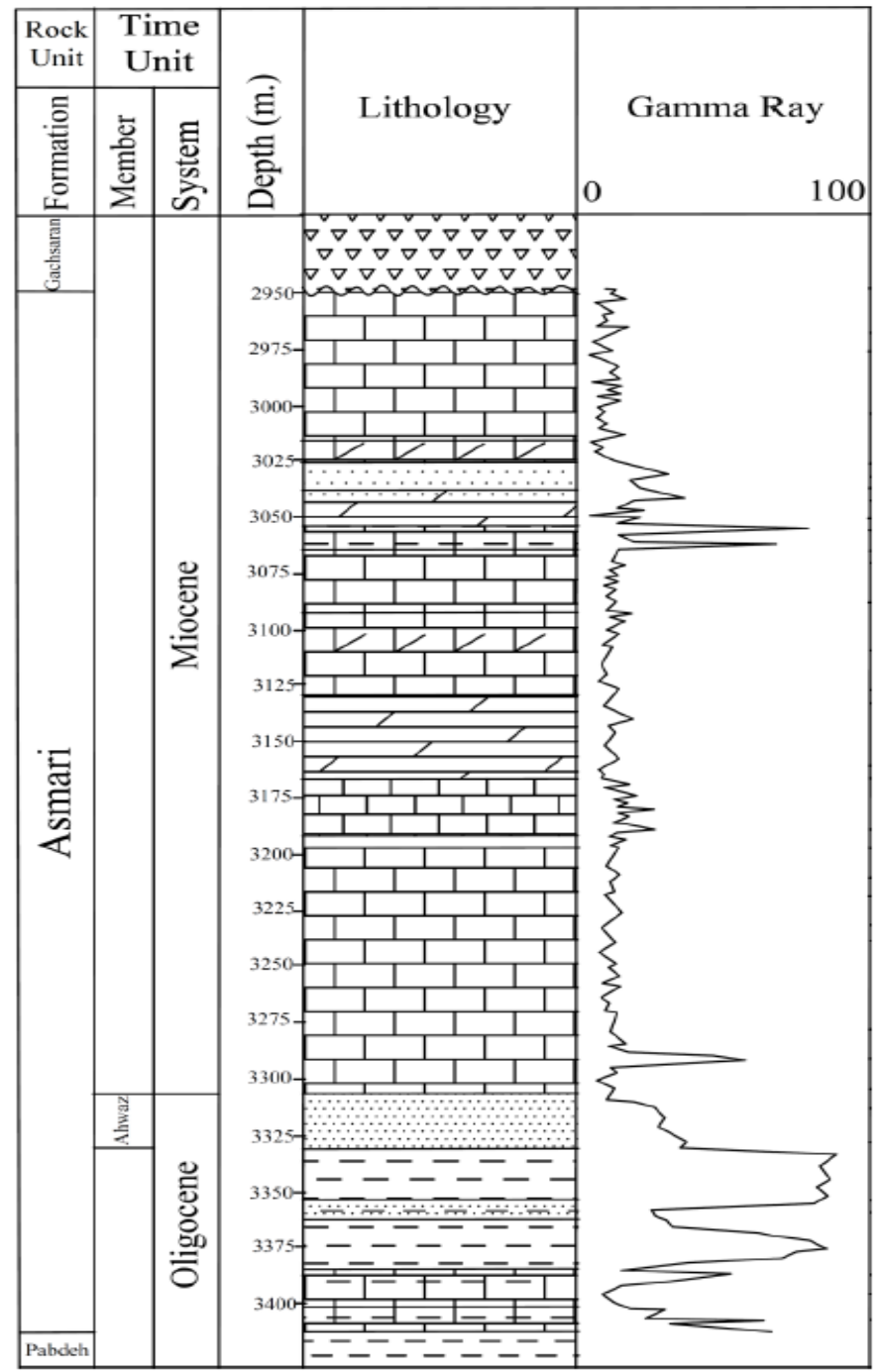

Figure. 4-Lithostratigraphic column of Asmari Formation 


\section{Biostratigraphy of Asmari Formation in Studied Well}

There are relatively diverse faunas, mostly including foraminiferans, in sediments of Asmari Formation. Based and this and considering the association of different forms, different models of biozonation of Oligo-Miocene sediments of Zagros area.

From biostratigraphic viewpoint, Asmari Formation is divided into three units, namely lower Asmari Unit with Oligocene age, Middle Asmari dating to early Miocene (Aquitanain), and higher Asmari dating back to early Miocene (Burdigalian) but this classification is not applicable everywhere (Thomas, 1948). The analysis of biostratigraphic characteristics of Mesozoic and Cenozoic deposits in Zagros area has led to introduction of 6 assemblage biozone with consecutive numbers of 54 to 59 in Asmari Formation (Wynd, 1965). Then, Adams and Bourgeois (1967) reviewed biostratigraphic characteristics of this lithological units and introduced 3 assemblage biozone and 2 sub-biozoone based on deposits of Asmari Formation as detailed before.

Considering the existence of diverse micro-faunas in Asmari Formation and changes in the abovementioned fossil set, different biozonation models are suggested for biostratigraphic classification of the deposits which often include introduction of social biozones (Wynd, 1965; Adams and Bourgeois, 1967). Recently, application of data concerning Strontium isotopes for determining the age of biological horizons of Oligo-Miocene deposits of Zagros area has drawn some attention (Ehrenberg et al, 2007). The obtained results seem to be promising when one considers rapid changes of ${ }^{87} \mathrm{Sr}{ }^{86} \mathrm{Sr}$ in going from Oligocene to Miocene as well as relative frequency of microfossils with proper maintenance in Asmari Formation (e.g. subsurface stratigraphic sections of Bibi-Hakimie, Maroon and Ahvaz fields and Shallow stratigraphic sections such as Khoiz). Laursen et al (2009) used data on analysis of relative changes of strontium isotpes and matching of stratigraphic distribution of foraminifera of sediments in Asmari Formation with above information so as offer a novel biozonation model for Oligo-Miocene deposits of Zagros area. In this regard, the Oligo-Miocene limit is defined with major modifications of stratigraphic distribution pattern (disappearance) of certain forms such as difference species of Archaias and Miogypsinoidescomplanatus.

In the analyzed samples, benthic foraminifera have higher relative frequency than planktonic foraminifera. Considering the stratigraphic distribution, the following fossil forms were identified:

Elphidium sp. 14, Triloculina tricarinata, Dendritina rangi, Peneroplis evolutus, Borelis melo curdica, Meandropsina anahensis.Pyrgo sp. 1, Elphidium sp. 1, Archaias sp., Archaias kirkukensis,asmaricus , Peneroplis thomasi, Peneroplis farsensis , Austrotrillina howchini,Miogypsinoides complanatus , Miogypsinoides spp., Valvulina sp. 1, Textularia sp., Bigenerina sp., Pseudolituonella reicheli, Heterostegina sp., Eulepidina dilatata, Glomospira spp., Quinqueloculina spp., Schlumbergerina spp., Archaias asmaricus, Miogypsina sp., Operculina complanata, Operculina sp., , Valvulina sp. 2, Boerlis sp., Globigerina sp.

Based on biozonation model offered by Laursen et al (2009), four social biozone were identified in the studied sediments as detailed in the following.

\section{Borelis melo curdica-B. melo melo Assemblage Zone:}

It is comparable with Borelismelo- Meandropsinairanica Assemblage Zone (Adams and Bourgeois, 1967). It extends in $65 \mathrm{~m}$ from limes of upper part of Asmari Formation with early Miocene age (Burdigalian). The presence of Borelis melo curdica is determined by certain forms such as Dendritinarangi, Discorbis sp., Elphidium sp. 1, Triloculinatricarinata, and Valvulina sp. 


\section{Miogypsina- Elphidium sp. 14- Peneroplis farsensis Assemblage Zone:}

This biozone is determined by presence of certain forms such as Elphidium sp. 14, Triloculina tricarinata, Triloculina trigonula, Heterillina sp., Valvulina sp. 2, Meandropsinairanica, Dendritinarangi. The age of this biozone is attributed to early Miocene (Aquitanain). It is comparable with Elphidium sp. 14-Miogypsina Assemblage Subzone (Adams and Bourgeois, 1967).

\section{Archaias asmaricus- A. hensoni-Miogypsinoides complanatus Assemblage Zone:}

This biozine is comparable with Archaiashensoni-Archaiasasmaricus Assemblage Subzone (Adams and Bourgeois, 1967). Considering the disappearance of different species of Archaias and matching this biological event with change in proportion of strontium isotopes in this stratigraphic horizon, the biozone was attributed to late Oligocene era (Ehrenberg et al, 2007; Laursen et al, 2009).

\section{4-Lepidocyclina-Operculina-Ditrupa Assemblage Zone}

With thickness of 230 and dating back to late Oligocene era, it is considered to be equivalent with Eulepidina-NephrolepidinaNummulites Assemblage Zone (Adams and Bourgeois, 1967). The biozone is determined by presence of certain forms such as Pseudolituonella reicheli, Heterostegina sp., Eulepidina dilatata, Lepidocyclina sp., Operculina complanata, Operculina sp., Nephrolepidina tournoueri, and Planorbulina spp. and lack of some other forms such as Archaias asmaricus, Archaias kirkukensis, Archaias sp., Austrotrillina asmariensis, Austrotrillina howchini.

\section{Variation of Gamma Range Logging along Stratigraphic Column and its Association with Sequence}

Today, sequence stratigraphy has adopted some novel forms due to increased number of field studies and higher tendency of industry to draw upon these studies so that sequence stratigraphy often refers to direct field studies by using seismic data, well logging especially Gamma range logging and integration of resulting data with data obtained from thin kernel sections (Taylor and Sellwood 2002; Michelsen and Danielsen 1996).

In most field studies, it is difficult to identify stratigraphic surfaces. On one hand, accuracy and resolution of seismic data are not sufficient for identifying system trackers. With help of Gamma range logging, one could determine system trackers with high accuracy through integrating it with lithological changes of facies (Michelsen and Danielsen, 1996).

In the present study, sequence stratigraphy was done through thin sections and Gamma range logging. The primary technique used by system trackets of vertical changes of facies is variation trend of Gamma range logging and interaction of biological allochems and changes in sea level.

Due to the fact that in carbonated ramps of similar slope, as high and progressive system trackets have highest generality and thickness, the level of Gamma radiation increased relatively in progressive system tracket. In maximum level of submergence, we witness highest level of radiation due to increased amount of clay minerals, glauconite and organic materials during quick progress of sea level or domination of open marine facies (Taylor and Sellwood, 2002; Lucia, 1990). This is while the level of closed radiation reduces relatively (sometimes very imperceptibly; progressive stacking pattern) or it has a fixed trend (incremental stacking pattern) (Aigner 1995; Kastner et al. 2008; Michelsen and Danielsen 1996).

Among the most significant shapes of Gamma diagram, one could point to the following ones:

\section{Bell Shape:}

Increased amount of Gamma beams as a result of increased amount of clay and decreased size of particles in upward direction makes this shape in Gamma diagram (Omoboriowo et al. 2012). It signifies 
progress of deposits towards earth (Siddiqui et al, 2013; Cant, 1992). This figure could be normal or serrated.

\section{Funnel Shape:}

Reduced amount of Gamma beams as a result of reduced volume of clay, coarsening of grains and increased proportion of carbonate to clastic sediments cause such a form in diagram of Gamma radiation (Serra, 1989; Oyanyan, 2012). The funnel shape of this figure signifies enlargement of particles in upward direction at the terminal section of delta in settings remote from deep parts of the sea (Siddiqui et al, 2013). This figure could be either normal or serrated.

Left Bow Shape:

Downsizing of grains in upward direction and different lithology (sequence of shale and lime) cause a left bow shape in diagram of Gamma radiation.

Right Bow Shape:

Upsizing of grains in upward direction and different lithology (sequence of shale and lime) cause a right bow shape in Gamma diagram.

Serrated (Irregular) Shape:

The shape is due to frequent lithological changes and it signifies a typical Gamma diagram. The diagram of sediments in sloping part of carbonate platform adopts such a form under the influence of waves (Siddiqui et al, 2013; Serra, 1989).

Right Boxcar Shape:

This shape is characterized by a high level of Gamma beams, definite but irregular borders and small changes and it could be found in mudstones and shale of settings which are remote from coastal areas (Siddique et al, 2013; Cant, 1992).

\section{Left Boxcar Shape:}

This state represents low level of Gamma beam, definite but irregular borders and low changes. It could be found in certain stones such as small-grained and medium-grained stones sandstones among mudstones and shale (Siddique et al, 2013; Cant, 1992).

Considering the existing facie sequence and changes of gamma range logging, one could identify the following sequences:

\section{Sequence 1:}

The upper limit of this sequence is of SB2 type. The lower limit of this sequence is located in Pabede Formation and it is out of operating range. TST part is identified by A1 facie which is an open marine shale. The limit is consistent with pb9000 line introduced by Averjani et al (2013).

This sequence limit is equivalent with lower sequence limit number 1 (Van Bochem et al, 2010). From this perspective, it dates back to 33 million years ago. In a study by Ehrenberg et al (2007), there is no equivalent level for this. This level is equivalent with pg30SB limit in sequences of Arabian Plate.

The ending of this shale limit which is associated with beginning part of Asmari Formation signifies MFS of this sequence. This level is equivalent with pg30MFS limit of Arabian plate sequences, nb8000 temporal limit (Averjani et al, 2013) and MFS I (Van Bochem et al, 2010). From temporal viewpoint, it dates back to 32.5 years ago. 
HST of this sequence is made up of middle ramp facie (B2) and it has low thickness. It is made up of lime and shale limestone. The upper limit of this sequence is associated with pb6000 timeline (Averjani et al, 2013), upper limit of sequence 1 (Van Bochem et al, 2010) and sequence limit of Ru30/Ch-10 (Ehrenberg et al, 2007). It dates back to 28.9 years ago.

In Arabian plate, no equivalent has been introduced for this level.

The closeness of this limit represents ending presence of Nummulites fossil and confirms the Rupelian age.

The sequence belongs to Rupelian era and its upper limit separates Rupelian from Chattian (Averjani et al, 2013).

The level of Gamma range logging in TST if one considers the shale content. In MFS limit, the value of GR is high and API is about 70. Then, the value reduces because of limeous lithology so that at the end of this sequence, we get to $10 \mathrm{API}$.

\section{Sequence 2:}

This sequence has SB2 upper and lower limit. TST of this sequence is made of A2 and A1 facies belonging to external ramp. The lower limit of this sequence is comparable with pb6000 limit (Averjani et al, 2013). The maximum flooding surface (MFS) is similar to previous sequence and belongs to A1 shale facie. The MFS is equivalent with nb7000 timeline (Averjani et al, 2013), pg40MFS level of Arabian plate and MFS II (Van Vochem et al, 2010). From viewpoint of absolute age, one could state that it dates back to 27.4 million years ago. HST of this sequence is made up of A1 facie. The upper limit of this sequence matches pb5000 timeline (Averjani et al, 2013), CH30 (Ehrenberg et al, 2007) and SB III (Van Bochem et al, 2010). Regarding absolute age, one could claim that it dates back to 25 years ago.

\section{Sequence 3:}

The sequence is made up of two parts: shale and sandstone. TST of this sequence is similar to sequences no. 1 and 2 and it is made of shale-bearing external ramp facie (A1). The difference is that at the beginning it has coastal zone facie (E2). The lower limit of this sequence matches pb5000 timeline (Averjani et al, 2013). MFS of this signal is the ending border of shale limit of external ramp. In this case, MFS is comparable with nb5000 timeline (Averjani et al, 2013), pg50mfs of Arabian plate limit and MFS III (Van Bochem et al, 2010). Based on this, it dates back to 25 years ago. TST of this sequence is made up of sandstones of Ahvaz section which is identifiable by facies of E1 and E2 coastal zone. The upper limit of third sedimentary sequence matches pb4000 (Averjani et al, 2013), $\mathrm{Ng} 10 \mathrm{SB}$ sequence limit in Arabian Plate and Aq10 (Ebrenberg et al, 2007) as well as SB IV (Van Bochem et al, 2010) which is temporally equivalent with 24 million years ago. The age of this late Chattian sequence and its upper border matches Oligo-Miocene border (Aquitanian-Chattian) (Averjani et al, 2013). The upper and lower limits of this sequence, considering lack of evidence of water outlet, is of SB2 type.

The Gamma range logging in TST section represents a high level of API with exception of initial layers which is shaly sand. Over it, there is a layer of shale the API of which ranges from 75 to 85 . This value attains 85 in MFS. Considering the fact that facies had turned into shale in MFS section, increased API seems to be logical. Then, in HST section this number reduces significantly and API goes through a decreasing trend due to presence of clean sandstones in coastal zone of Ahvaz Section and they get to 10.

Depositional Sequence 4: 
This sequence has higher diversity in facies compared with previous ones. The lower sequence of this sequence, which is the upper border of third sequence, was described before. TST part of the fourth sequence is made up of external ramp facie (A3). The ending part of this facie represents the highest level of progress by the sequence and signifies its MFS. Maximum flooding surface (MFS) of sea in the fourth sequence is equivalent with nb4000 timeline (Averjani et al, 2013) and MFS IV (Van Bochem et al, 2010) which is temporally equivalent with 22.8 million years ago. HST of this sequence is made up of tidal flat facies which are observed in initial part of D1, D3 and D1 facies. The latter ends the fourth sequence. The upper limit of this sequence matches pb3000 (Averjani et al, 2013), Aq20/Bu-10 (Ehrenberg et al, 2007) and SB V (Van Bochem et al, 2010). The age of fourth depositional sequence is early Aquitanain (Averjani et al, 2013). The upper and lower limit of this sequence is of SB2 type when one considers lack of any evidence of water outlet.

The level of Gamma range logging in this sequence is generally low. As stated before, all these sequences are limeous. In general, TST represents a profile of increasing API so that in lower part of this section, this quickly increases from about 10 to 60 in MFS. This signifies that limeous layers of MFS section includes more clay materials. Then, the number reduces due to limeous lithology so that it is equal with $10 \mathrm{API}$ at the end of this sequence. Of course, this reduction occurs frequently and ranges between 10 and 15.

\section{Sequence 5:}

This sequence is thicker than previous ones. The lower limit of this limit is the upper limit of fourth sequence which was detailed before. TST of this sequence is made up of middle ramp facie. B3, B3 and then B3 and B1 are observed. Maximum MFS is witnessed at the end of B1 facie which shows a deeper environment than all other facies. This MFS is comparable with nb2000 timeline (Averjani et al, 2013) and MFS V (Van Bochem et al, 2010) which is temporally equivalent with 20.9 years ago.

HST of this sequence is made up of internal ramp facies and tidal flat; this signifies a digressive trend so that tidal flat facies are located over internal ramp. Over them, C2, D3, D1, D3 and D1 facies are respectively located and sequence finally ends. The higher and lower limit of this sequence, considering lack of evidence of water outlet, is of SB2 type. The upper limit of this sequence is comparable with sequence limits of pb2000 (Averjani et al, 2013), Bu-20 (Ehrenberg et al, 2007) and SBVI (Van Bochem et al, 2010) which is equivalent with 20.5 years ago. The biostratigraphic evidence confirms Burdigalian age in upper limit. The age of fifth sedimentary sequence is late Aquitanain and upper limit of it matches Burdigalian-Aquitanain limit (Averjani, 2013). Considering lack of evidence of water outlet, the upper and lower limit of this sequence are of SB2 type.

Gamma range logging in the sequence has generally low variation and high numerical value. The API value of totally limeous TST part ranges between 10 and 15. This value for terminal dolomites of this sequence is less than other facies.

\section{Sequence 6:}

This sequence is thicker than previous ones. The lower limit of this sequence, considering lack of evidence of water outlet, is of SB2 type. The lower limit of this sequence, which is higher limit of fifth sequence, inhibits its iteration. This limit is comparable with pb2000 timeline (Averjani et al, 2013). TST of this sequence is made up of external ramp facie. The A2, A3, and A4 facies represent progressive part of this sequence. A2 sequence refers to MFS of this sequence. Maximum MFS in sixth sequence is equivalent with nb1000 timeline (Averjani et al, 2013), MFS VI (Van Bochem et al, 2010) and Ng10 mfs of Arabian plate. It is temporally equivalent with 19.6 million years ago.

HIS of sixth sequence starts with tidal flat facie (D2, D3), continues with coastal zone (E1 and E2) and ends with internal ramp (C2, C3 and C5). The upper line of this sequence matches Gachsaran Formation which is of SB1 type if one considers lack of evidence of water outlet. The limit of this 
sequence matches Ng20SB of Arabian Plate and SB VII (Van Bochem et al, 2010) It is temporally equivalent of 18.5 million years.

Gamma range logging in starting part of TST, which is made up of lime, ranges between 10 and 15 API. But for terminal layers made up of Shaly lime, it increases rapidly and attains 70 API. In fact, this value represents the end of TST and MFS limit. Considering the fact that facies are made of shale, increased API at MFS section is logical. Then, this value decreases significantly in HST and API in MFS was about 75 . In this section, considering clean sandstones and dolomites without clay and limeous minerals, MFS reduced significantly to 10 .

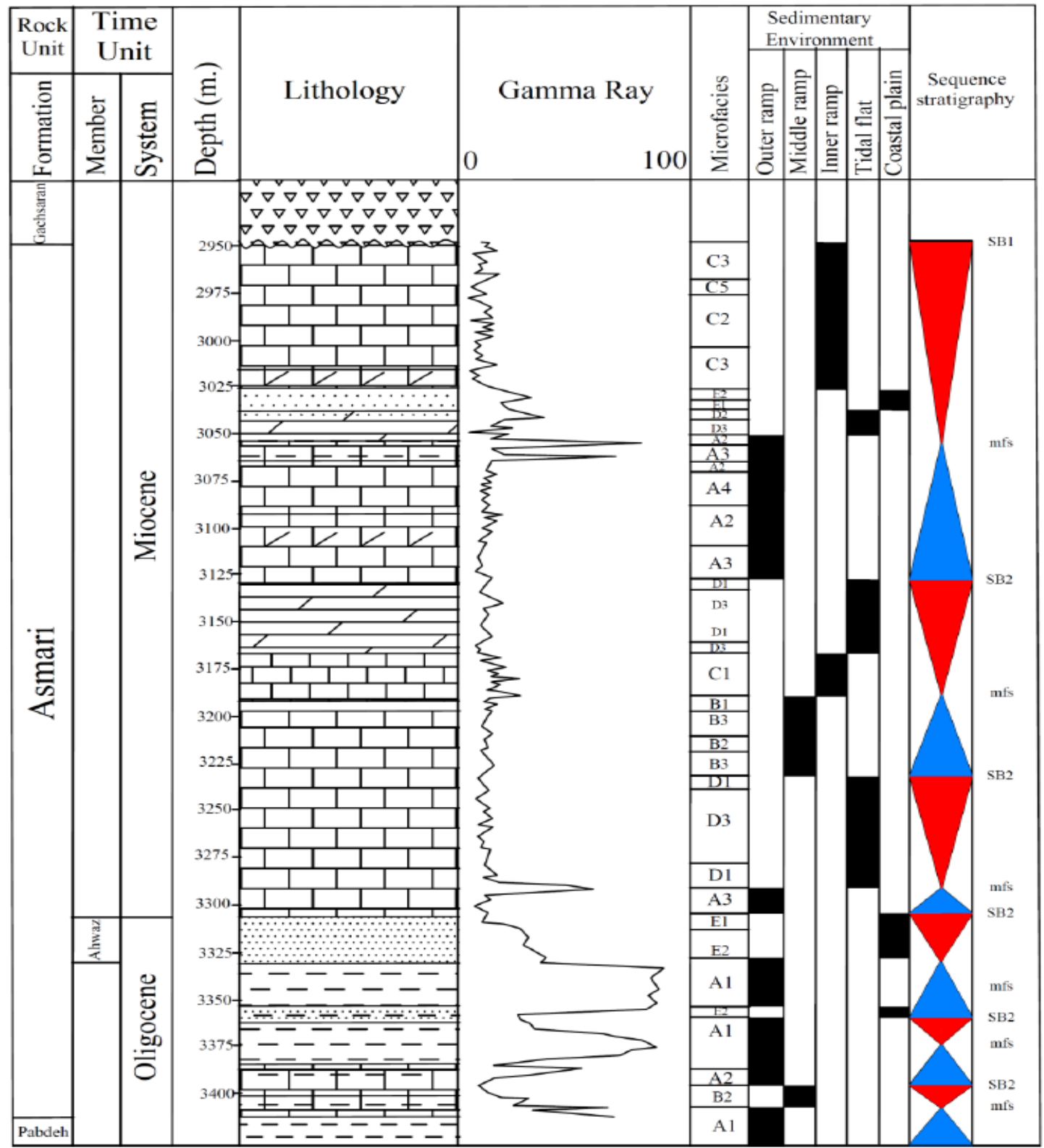

Figure. 5-Sequence stratigraphy of sediments in Asmari Formation of studied well 


\section{Results}

In the present study, sequence stratigraphy of Asmari Formation and over one of the wells of the field was reviewed. In addition to typical method of using microfacies in determining sequences, Gamma range logging was also done and obtained results were analyzed.

In this well, Asmari Formation is located on shaly Pabede Formation and below Gachsaran Formation. The lower limit of this formation and Pabede Formation is gradually over it but below Gachsaran Formation with certain discontinuities. Thickness of Asmari Formation is equivalent with $452 \mathrm{~m}$. Regarding this well and from lithostratigraphic viewpoint, Asmari Formation in lower parts is made up of lime, shaly lime, and sandstone which when moving from middle to upper parts, we find dolomite, lime, dolomitic lime, shaly lime and sandstone.

Based on existing facie sequence and changes in Gamma range logging, the following 6 sequences were identified:

Lower limits of sequence 1 is equivalent with lower limit of sequence no. 1 in Van Bochem et al (2010) and pg30SB limit of sequences of Arabian plate. Consequently, it temporally dates back to 33 million years ago. MFS of this sequence is equivalent with pg30mfs limit of Arabian plan and MFS I (Van Bochem et al, 2010). From temporal viewpoint, it is equivalent with 32.5 years ago. The upper limit of this sequence is adjacent with upper limit of sequence 1 (Van Bochem et al, 2010) and Ru30/Ch-10 sequence (Ehrenberg et al, 2007). From temporal perspective, it dates back to 28.9 years ago. The age of this sequence is Rupelian and upper limit of it separates Rupelian from Chattian.

MFS of second sequence has similar limit with pg40mfs of Arabian Plate and MFS II (Van Bochem et al, 2010). Based on this, the sequence dates back to 25 million years ago. The upper limit of third depositional sequence matches Ng10SB sequence in Arabian plate, Aq10 (Ehrenberg et al, 2007) and SB IV (Van Bochem et al, 2010). Temporally, it dates back to 24 million years ago. The age of this sequence is late Chattian and its upper limit matches Oligo-Miocene limit (Aquitanian-Chattian).

Maximum MFS in fourth sequence matches temporal limit of MFS IV (Van Bochem et al, 2010) which dates back to 22.8 million years ago. The upper limit of this sequence matches Aq20/Bu-10 (Ehrenberg et al, 2007) and SB V (Van Bochem et al, 2010). The age of fourth depositional sequence is early Aquitanain (Averjani et al, 2013).

MFS of sequence 5 could match MFS V limit (Van Bochem et al, 2010) and as a result, it dates back to 20.9 million years ago. The upper limit of this sequence is comparable with sequence limits of Bu-20 (Ehrenberg et al, 2007) and SBVI (Van Bochem et al, 2010) which is temporally equivalent to 20.5 million years ago. The age of fifth depositional sequence is late Aquitanain and its upper limit matches Burdigalian-Aquitanain limit.

Maximum MFS for fourth sequence matches MFS VI (Van Bochem et al, 2010) and Ng10mfs level of Arabian plate. It dates back to 19.6 million years ago. The limit of this sequence matches $\mathrm{Ng} 20 \mathrm{SB}$ of Arabian plate and SB VII (Van Bochem et al, 2010) which dates back to 18.5 million years.

With exception of upper limit of sequence 6 which is associated with Gachsaran Formation and considering the fact that there is evidence of water outlet of SB1 type, all sequence limits is of SB2 type.

Gamma range logging variation for sequences follows a definite trend generally. In TST sections, the value of API increases when going from bottom to the head. In MFS, it attains a maximum and in HST, the value decreases. Clean rocks such as sandstone, dolomite and limestone have low API while shale and shaly limestone represents higher API. 


\section{References}

Adabi, M, H. (1996). Sedimentology and geochemistry of upper Jurassic (Iran) and Precambrian (Tasmania) carbonates.Un publ. ph.D.Thesis, uni . Tasmania, Australia, 400.

Adams, T.D \& Bourgeios, F. (1967). Asmari biostoatigraphy, geological and exploration, Div, Jooc, Report No. 1074, Tehran.

Adames, T. D. (1969). The Asmari Formation of lurestan and Khuzestan provinces. I.o.o.c. Report, No, 1154. (Unpublished).

Agha Nabati, A. (2005). Geology of Iran, Geology Organization, 707.

Ahr, W. M \&Ross, S.L. (1982). Chapel (Mississippian) biohermal reservoir in the Hardeman Basin, Texas (abs):If coast Assoiation of Geological Societies Transactions, Y.32, 185-193.

Ahr, W.M. (1973). Carbonate ramp (A historical review). In: Writh, V. P \&Burchette, T. P.(eds), (1998), carbonate Ramps, sour, Geol.Society, London, special publ., 149, 205-227.

Al Sharhan, A. S. (1993). Facies and sedimentary environment of the Permian carbonates (Kuff Formation) in the United Arab Emirates: Sedimentary Geology, 84, 89-99.

Alsharhan, A. S \&Kendall, C. G. St. C., (2002). Holocene coastal carbonates and evaporites of the southern Arabian Gulf and their ancient analogues, Earth-Science Reviews, 61, 191-243.

Alsharhan, A. S \& Nairn, A. E. M. (1990). Sedimentary basins and petroleum geology of the Middle East. Elsevier, Amsterdam, 773.

Alavi, M. (1994). Tectonics of the Zagros orogenic belt of Iran: new data and interpretations.Tectonophysics, 299, 211-238.

Alavi, M. (2004). Regional stratigraphy of the Zagros fold - thrust Bell of Iran and its proforland evolution, Am. Journal of science, 304, 1-20 .

Aram, A. (2005). Sequence stratigraphy of Asmari Formation and study of its depositional environment in Ramin Oilfield, M. A dissertation, Tehran University, 132.

Badio Z, K.(1973). The dorag dolomitization model application to the middle Ordovician of Wisconsin: jour.sed.petrology., 43, 965-984.

Bathurst, R.G. (1975). Carbonate sediments and their Diagenesis: Development in sediment logy, Amsterdam, Elsevier, 658.

Behzadi, S. (2003). Diagenesis and hydrogeochemistry of oligomiocenedeposits (Ghar-Shapur Area, Master Disserttion, Shahid Beheshti University, 146.

Butler, G. P. (1970). Holocene gypsum and anhydrite of the Abu Dhabi Sabkha, Trucial Coast: An alternative explanation of origin, Third symposium on salt. N. ohio geology. Soc, 1, 120-152.

Butler, G. P. (1969). Modern evaporate deposition and geochemistry of co-existing brines, the sabkha, Trucial Coast, Arabia Gulf. J. Sediment. Petrol., v. 59, 70-89.

Butler, G.P, Harris,P. M\& Kendall,C.G.St.C. (1982). Recent evaprites from the Abu Dhabi coastal flats .In: Deposition and Diagenetic Spectra of evaporates (Ed. By C.R Handford, R.G.Loucks and G.R. Davies) S.E.P.M. core workshop 3, 33-4.

Darvish Zade, A. (2002). Geology of Iran, Amir Kabir Publication, 625. 
Feiz Nia, S. (1999). Carbonated depositional rocks. Qods Razavi, 304.

Hassanvand, A. (2007). Sequence stratigraphy of Asmari Formation and reconstruction of its depositional environment in Parsi Oilfield, Masterly Dissertation, Tehran University, 130.

Kimiagari, A. (2006). Biostratigraphy of microscopic facies and sequence stratigraphy of Asmari Formation of Groopi Anticline (Lali) up to Khoinz Mountain (Behbahan), Doctorate Dissertation of Stratigraphy and Paleontology. Isfahan University, 220.

Maleki Kheime Sari, S. (2000). Petrography and interpretation of depositional environment of Asmari Formation in northern rim of Dezful Depression. Masterly Dissertation, Shahid Beheshti University. 247.

Motiee, H. (1994). Geology of Iran (stratigraphy of Zagros), Geology Organization of Iran, , Journal of Geology of Iran, 1-2, 1010.

Naseh, M. (2003). Petrography and depositional environment of Asmari Reservoir in Aghajari Oilfield, Masterly Dissertation, Shahid Beheshti University.

Omidpur, A. (2005). Stratigraphic sequence of Asmari Formation and its diagenetic analysis and review of depositional environment in Koopal Oilfield, M. A. dissertation, Tehran University, 178.

Rahimpur, B. H. (2006). Carbonate lithology: Association between digenesis and porosity evolution, Tehran University Press, 478.

Raisi, A, V. (1999). The study of facies and depositional environment of Asmari Formation in Southern Dezful Depression, Masterly Dissertation, Tarbiate-Moalem University.

Sairfian, A. (1994). Oil geology. Zareh Press.

.....(1994). Basic principles of well excavation (for Feologists), Zareh Press.

Shoshtarian, F. (2004). Geochemistry, depositional environment and study of diagenesis trend in carbonated deposits of Asmari Formation in Tang Gole-Torsh of Asmari Anticline, Masterly Dissertation, Tehran University Press, 78.

Tehrani, K. (1999). Applied micro-paleontology, 1 and 2, Tehran University, 597. 